\title{
Proteinograma sérico de éguas com placentite ascendente e seus respectivos neonatos: dados preliminares
}

\author{
[Serum protein concentrationin mares with ascendingplacentitis and \\ their newborns: preliminary data] \\ C. Haetinger ${ }^{1}$, B.R. Curcio $^{2}$, L.A. Lins $^{2 *}$, V. Müler ${ }^{3}$, L.S. Feijo ${ }^{1}$, F.M. Pazinato ${ }^{1}$, \\ L.A. Amaral ${ }^{1}$, C.E.W. Nogueira ${ }^{2}$ \\ ${ }^{1}$ Aluna de pós-graduação - Faculdade de Veterinária - UFPel - Pelotas, RS \\ ${ }^{2}$ Faculdade de Veterinária - UFPel - Pelotas, RS \\ ${ }^{3}$ Aluna de graduação - Faculdade de Veterinária - UFPel - Pelotas, RS

\section{RESUMO}

Este estudo teve por objetivo estabelecer o proteinograma sérico em éguas com placentite induzida e em seus respectivos neonatos. Foram coletadas amostras de sangue das éguas em oito momentos diferentes e dos potros em quatro momentos. Para obtenção da concentração das frações proteicas, utilizou-se eletroforese em gel de acrilaminada contendo dodecil sulfato de sódio (SDS-PAGE). No método utilizado, foram observadas 23 bandas proteicas, cujos pesos moleculares variaram de $16 \mathrm{KDa}$ a $245 \mathrm{KDa}$, sendo possível a identificação das seguintes frações: $175 \mathrm{KDa}, 102 \mathrm{KDa}, 83 \mathrm{KDa}, 63 \mathrm{KDa}, 50 \mathrm{KDa}, 41 \mathrm{KDa}$, $39 \mathrm{KDa}$ e $28 \mathrm{KDa}$. De todas as bandas proteicas encontradas, somente as de $39 \mathrm{KDa}$ e $41 \mathrm{KDa}$ apresentaram alteração na cinética nos momentos avaliados. De acordo com a solução marcadora, pode-se sugerir que essas proteínas seriam $\alpha 1$-glicoproteína ácida $(39 \mathrm{KDa})$ e haptoglobina $(41 \mathrm{KDa})$. A concentração de imunoglobulinas nos potros apresentou aumento significativo a partir das 12 horas de nascimento. Não está elucidado se estes níveis refletem a persistência do processo inflamatório placentário ou se são alterações fisiológicas do periparto. Não foram observadas alterações na cinética das proteínas nos potros nas primeiras 48 horas.

Palavras-chave: haptoglobina, $\alpha 1$-glicoproteína ácida, obstetrícia equina, proteínas de fase aguda

\begin{abstract}
The aim of this paper was to identify the serum acute phase protein concentration in mares with induced placentitis and their neonates. Blood samples were collected from the mares in 8 different moments, and from the foals, in 4 moments. To obtain the concentration of protein fractions acrilaminada gel electrophoresis in sodium dodecyl sulfate (SDS-PAGE) was used. In the used method 23 protein bands whose molecular weights ranged from $16 \mathrm{kDa}$ to $245 \mathrm{kDa}$ were observed, it is possible to identify the following fractions: $175 \mathrm{kDa}, 102 \mathrm{kDa}, 83 \mathrm{kDa}, 63 \mathrm{kDa}, 50 \mathrm{kDa}, 41 \mathrm{kDa}, 39 \mathrm{kDa}$ and $28 \mathrm{kDa}$. Of all the protein bands found only the 39KDa and 41KDa have changes in the kinetics in the evaluated times. According to the marker solution, we would suggest that these proteins are $\alpha 1$-acid glycoprotein $(39 \mathrm{kDa})$ and haptoglobin $(41 \mathrm{kDa})$. The concentration of immunoglobulins in foals increased significantly from 12 hours of birth.
\end{abstract}

Keywords:Haptoglobin, $\alpha 1$-acid glycoprotein, equine obstetrics, acute phase proteins

Recebido em 15 de outubro de 2015

Aceito em 29 de março de 2016

*Autor para correspondência (corresponding author)

E-mail: lucianaalins@yahoo.com.br 


\section{INTRODUÇÃOO}

A placentite ascendente na égua é uma das principais causas de parto prematuro, aborto e nascimento de potros comprometidos (LeBlanc, 2010), sendo o Streptococcus equi, subespécie zooepidemicus, o principal agente causador (Giles et al., 1993). A pesquisa para se encontrarem marcadores precoces da inflamação vem sendo foco nas medicinas humana $\mathrm{e}$ veterinária ao longo dos anos, utilizando-se principalmente a identificação bioquímica das proteínas de fase aguda (PFA) como marcador do grau da inflamação (Crisman et al., 2008). As PFAs são proteínas sanguíneas que alteram sua concentração em processos inflamatórios, infecciosos ou estresse (Murata et al., 2004). O emprego da técnica SDS-PAGE em medicina veterinária pode ser útil na avaliação da cinética das proteínas de fase aguda de resposta inflamatória, facilitando a definição do diagnóstico das doenças animais (Fagliari et al., 2003). O objetivo deste estudo é estabelecer o proteinograma sérico em éguas com placentite induzida e em seus respectivos neonatos.

O estudo foi realizado com o plantel de éguas do Centro de Ensino e Experimentação em Equinocultura da Palma (CEEP), da Universidade Federal de Pelotas, no município de Capão do Leão, Rio Grande do Sul (31 48'08.2"S; $\left.52^{\circ} 29^{\prime} 51.4^{\prime \prime} \mathrm{O}\right)$, durante a temporada reprodutiva 2012-2013. Para o modelo experimental, foram utilizadas oito éguas mestiças, com média de $11 \pm 2$ anos e média de peso de $437 \pm 22 \mathrm{~kg}$, e seus respectivos neonatos. Este estudo foi aprovado pelo Comitê de Ética e Experimentação Animal da Universidade Federal de Pelotas, sob nº 3072/2013.

As éguas foram submetidas à indução de placentite ascendente, por meio da infusão intracervical de Streptococcus equi, subespécie zooepidemicus, na concentração de $10^{7} \mathrm{UFC}$, entre os dias 290-300 de gestação, conforme protocolo descrito por Bailey et al. (2010).

Todas as éguas desenvolveram sinais clínicos de placentite, como espessamento da junção uteroplacentária e descolamento placentário 24$48 \mathrm{~h}$ após a indução, avaliados por ultrassonografia. Também foi observada secreção vaginal mucopurulenta, sendo coletada para avaliação microbiológica e citológica, quando foi identificado crescimento de $S$. equizooepidemicus e presença de células inflamatórias por citologia, determinando o diagnóstico clínico de placentite. As éguas foram tratadas com sulfametoxazol e trimetoprim (Trissulfin ${ }^{\circledR}$, sulfametoxazol e trimetoprim, Ouro Fino Agronegócio, Brasil), na dose de $30 \mathrm{mg} / \mathrm{kg}$, a cada 12 horas, além de flunixinmeglumine (Desflan®, flunixinmeglumine, Ouro Fino Agronegócio, Brasil), na dose 1,1mg/kg, a cada 24 horas, sendo iniciado a partir de 48 horas de indução. Todos os partos foram assistidos para avaliar a necessidade de intervenção. Após a expulsão da placenta, foram coletados fragmentos de sete pontos desta, conforme $\mathrm{o}$ método de Schlafer (2004), os quais foram encaminhados para avaliação histopatológica. Das oito éguas avaliadas, somente quatro apresentaram, no momento do parto, lesões histopatológicas de placentite aguda caracterizadas por infiltrados celulares mistos, predominantemente histiolinfocitários, com presença de alguns neutrófilos, conforme o padrão descrito por Hong et al. (1993) e Lins et al. (2012). Foi realizada a comparação do proteinograma sérico entre as éguas com lesões compatíveis com placentite aguda $(n=4)$ contra as éguas que não apresentaram esse padrão de placenta $(n=4)$.

A assistência imediata ao neonato constou de limpeza das vias aéreas e ventilação com auxílio de ambu, além de oferta de colostro até uma hora apos o parto. Na ausência ou no retardo do reflexo de sucção, o colostro era fornecido via sonda nasogástrica. Os neonatos foram tratados com ampicilina (Cilinon ${ }^{\circledR}$, ampicilina sódica, Ariston, Brasil), na dose $22 \mathrm{mg} / \mathrm{kg}$ e intervalo de seis horas, e flunixinmeglumine (Desflan ${ }^{\circledR}$, flunixinmeglumine, Ouro Fino Agronegócio, Brasil), na dose de $1,1 \mathrm{mg} / \mathrm{kg}$, a cada oito horas.

Todos os animais foram submetidos à coleta de sangue e o soro foi separado e armazenado a $20^{\circ} \mathrm{C}$. Foram coletadas amostras de sangue das éguas em oito momentos: 60 dias pré-parto (M1), 30 dias pré-parto (M2), no dia da indução (M3), 24 horas (M4) e 48 horas após a indução (M5), no dia que antecedeu o parto (M6), imediatamente após o parto (M7) e 24 horas após 
o parto (M8). Os neonatos foram submetidos a coletas de sangue em quatro momentos: imediatamente após o nascimento $(\mathrm{C} 1), 12$ horas (C2), 24 horas (C3) e 48 horas após o nascimento (C4).

O processamento das amostras foi realizado no Laboratório de Apoio à Pesquisa do Departamento de Clínica e Cirurgia Veterinária da Unesp - Jaboticabal. A concentração plasmática de proteína total foi determinada pelo método colorimétrico, por reação com o biureto, utilizando-se kit comercial (Labtest $\AA$ ). Para obtenção da concentração das frações proteicas, utilizou-se eletroforese em gel de acrilaminada contendo dodecil sulfato de sódio (SDS-PAGE), conforme técnica descrita por Laemmli (1970). Após o fracionamento, o gel foi corado durante 10 minutos em solução de azul de coomassie e, em seguida, colocado em solução de ácido acético a $7 \%$ para retirar o excesso de corante, até que as frações proteicas se apresentassem nítidas. As concentrações dessas proteínas foram determinadas em densitômetro computadorizado (Shimadzu CS 9301 - Tokio, Japan). Como referência, utilizou-se uma solução marcadora (Sigma - Saint Louis, EUA) com pesos moleculares 29.000, 45.000, 66.000, 97.400, 116.000 e 205.000 dáltons (Da), além de proteínas purificadas - albumina, $\operatorname{IgG}$, haptoglobina e transferrina.

Para se avaliar a influência dos diferentes momentos nas variações dos proteinogramas séricos, foi realizada análise de variância simples pelo teste One Way AOV, com a comparação entre médias por meio do teste LSD. Os dados que não apresentaram distribuição normal no teste de normalidade Shapiro-Wilk foram analisados pelo teste Kruskal-Wallis One-Way Nonparametric AOV. Para se avaliar a correlação entre as bandas proteicas identificadas em éguas e potros, foi realizado o teste de correlação de Pearson. As comparações foram realizadas entre todos os momentos avaliados das éguas, contra os dois momentos avaliados nos potros. Foi utilizado o software Statistix 9.0 para a análise.

No método utilizado, foram observadas 23 bandas proteicas, cujos pesos moleculares variaram de $16 \mathrm{KDa}$ a $245 \mathrm{KDa}$, sendo possível a identificação das seguintes frações: $175 \mathrm{KDa}$, $102 \mathrm{KDa}, 83 \mathrm{KDa}, 63 \mathrm{KDa}, 50 \mathrm{KDa}, 41 \mathrm{KDa}$,
$39 \mathrm{KDa}$ e $28 \mathrm{KDa}$. De todas as bandas proteicas encontradas, somente as de 39KDa e $41 \mathrm{KDa}$ apresentaram alteração na cinética nos momentos avaliados. De acordo com a solução marcadora (Sigma - Saint Louis, EUA), pode-se sugerir que essas proteínas seriam $\alpha 1$-glicoproteína ácida (39KDa) e haptoglobina (41KDa). Nas Tab. 1 e 2, são demonstrados os níveis dos valores das frações proteicas identificados nas éguas e nos potros, respectivamente.

A concentração da fração proteica de $39 \mathrm{Kda}(\alpha 1$ glicoproteína ácida) nas éguas apresentou crescimento gradativo a partir das 48 horas após a indução da placentite. Já a PFA 41KDa (haptoglobina) demonstrou curva de crescimento gradativo conforme aproximação do parto, não apresentando aumento significativo entre os momentos. Não foi observada diferença entre os grupos de éguas, de acordo com as lesões histopatológicas da placenta, para nenhuma das proteínas testadas nos diferentes momentos. Nas comparações realizadas entre as éguas e os potros, não houve correlação entre os valores das proteínas nas duas categorias e nos diferentes momentos.

No presente estudo, a fração proteica de39KDa ( $\alpha 1$-glicoproteína ácida) se destacou das demais identificadas na eletroforese, apresentando aumento na sua concentração a partir de 48 horas após a inoculação da bactéria, atingindo maiores concentrações no dia prévio ao parto e após o parto. De acordo com Eckersall e Bell (2010), os níveis das proteínas de fase aguda apresentam um pico em seu acréscimo a partir de 24-48 horas após o estímulo, o que ocorreu nos dados do presente estudo. No entanto, para os mesmos autores, os níveis devem rapidamente declinar quando na extinção do processo.

Não houve diferença entre os valores das proteínas nas éguas que apresentaram placentite no momento do parto para as que não demonstraram alteração placentária no histopatológico, o que pode sugerir que este acréscimo nas taxas das frações proteicas de 39KDa ( $\alpha 1$-glicoproteína ácida) ocorre de forma fisiológica no periparto.

Os níveis da fração proteica de 39KDa (haptoglobina) nas éguas demonstraram uma curva semelhante e, apesar de os aumentos não serem significativos, são também indicativos de 
que houve resposta dessa proteína ao estímulo, sem regressão após o tratamento. Por serem ambas PFA do tipo positivas, seus níveis elevados ou crescentes indicam presença e persistência do estímulo inflamatório ((Takiguchi et al., 1990; Kaneko et al., 1997). Canisso et al. (2014) demonstraram elevação dos níveis plasmáticos de haptoglobina em éguas com placentite induzida. Entretanto, não está esclarecido se esses níveis apresentam comportamento similar em placentite espontânea (Canisso et al., 2015).

Em estudo de Bailey et al. (2010), mediante tratamento à base de sulfametoxazol e trimetoprim na dose de $30 \mathrm{mg} / \mathrm{kg}$, em modelo experimental de placentite induzida, foi possível prolongar a gestação de éguas com placentite ascendente. No entanto, para os mesmos autores, o protocolo terapêutico não foi eficaz em eliminar completamente a infecção bacteriana no útero ou em aumentar a viabilidade neonatal. Assim, os níveis crescentes das frações proteicas após a indução da placentite podem indicar a persistência do processo inflamatório.

Os potros apresentaram aumento na concentração de $\operatorname{IgG}$ a partir das 12 horas de nascimento, que representa a concentração de imunoglobulinas adquiridas por transferência passiva, através do colostro. Aqueles potros que apresentaram graus de imaturidade apresentaram esse mesmo acréscimo, o que se justifica em função da assistência neonatal com administração de colostro via sonda nasogástrica nos neonatos que não apresentaram reflexo de sucção. $\mathrm{O}$ colostro fornece uma fonte imediata de imunoglobulinas, e a falha na absorção ou na transferência passiva destes anticorpos representa um importante fator de risco para a infecção (Cohen, 1994).

Nos potros, não foram observadas alterações na cinética das frações proteicas durante o período avaliado neste estudo, contemplando desde o nascimento até as primeiras 48 horas de vida.

No presente estudo, foi estabelecido o proteinograma sérico em éguas com placentite induzida, em que ficou demonstrado um aumento crescente dos níveis das frações proteicas de 39Kda ( $\alpha 1$-glicoproteína ácida) e 41Kda (haptoglobina) 48 horas após a indução de placentite, até o momento do parto. Na avaliação do proteinograma dos neonatos, não houve alteração na cinética das proteínas avaliadas durante o período.

Tabela 1. Média e desvio-padrão das concentrações das frações proteicas $(\mathrm{mg} / \mathrm{dL})$ e da proteína total (g/dL) nas éguas com placentite ascendente nos momentos: 60 (M1) e 30 dias pré-parto (M2), no dia da indução da placentite (M3), 24 horas (M4) e 48 horas após a indução (M5), no dia que antecedeu o parto (M6), imediatamente após (M7) e 24 horas após o parto (M8)

\begin{tabular}{|c|c|c|c|c|c|c|c|c|c|c|c|c|c|c|c|c|}
\hline $\begin{array}{l}\text { Proteínas/ } \\
\text { Frações } \\
\text { proteicas }\end{array}$ & $\mathrm{N}$ & M1 & $\mathrm{N}$ & M2 & $\mathrm{N}$ & M3 & $\mathrm{N}$ & M4 & $\mathrm{N}$ & M5 & $\mathrm{N}$ & M6 & $\mathrm{N}$ & M7 & $\mathrm{N}$ & M8 \\
\hline $\mathrm{PT}(\mathrm{g} / \mathrm{dL})$ & 8 & $8275,0 \pm$ & 7 & $7742,9 \pm$ & 7 & $8172,9 \pm$ & 4 & $7985,7 \pm$ & 6 & $8233,3 \pm$ & 7 & $7771,4 \pm$ & 8 & $8587,5 \pm$ & 6 & $8083,3 \pm$ \\
\hline & & $361,54 \mathrm{AB}$ & & $472,08 \mathrm{~B}$ & & $703,20 \mathrm{AB}$ & & $740,33 \mathrm{AB}$ & & $508,59 \mathrm{AB}$ & & $468,03 \mathrm{~B}$ & & $768,00 \mathrm{~A}$ & & $507,61 \mathrm{AB}$ \\
\hline $63 \mathrm{KDa}$ & 8 & $\begin{array}{l}4366,9 \pm \\
1604,3 \mathrm{~A}\end{array}$ & 7 & $\begin{array}{c}4495,3 \pm \\
425,51 \mathrm{ABC}\end{array}$ & 7 & $\begin{array}{c}4602,0 \pm \\
508,66 \mathrm{ABC}\end{array}$ & 4 & $\begin{array}{c}4263,6 \pm \\
604,80 \mathrm{BC}\end{array}$ & 6 & $\begin{array}{c}4748,7 \pm \\
598,41 \mathrm{AC}\end{array}$ & 7 & $\begin{array}{l}4134,4 \pm \\
276,69 \mathrm{C}\end{array}$ & 8 & $\begin{array}{l}4916,9 \pm \\
614,49 \mathrm{~A}\end{array}$ & 6 & $\begin{array}{c}4358,3 \pm \\
393,61 \mathrm{ABC}\end{array}$ \\
\hline $102 \mathrm{KDa}$ & 8 & $\begin{array}{l}79,12 \pm \\
214,12\end{array}$ & 7 & $\begin{array}{c}3,42 \pm \\
2,22\end{array}$ & 7 & $\begin{array}{c}5,85 \pm \\
3,07\end{array}$ & 4 & $\begin{array}{c}4,71 \pm \\
3,59\end{array}$ & 6 & $\begin{array}{c}3,83 \pm \\
3,25\end{array}$ & 7 & $\begin{array}{c}5,00 \pm \\
4,93\end{array}$ & 8 & $\begin{array}{c}6,37 \pm \\
7,38\end{array}$ & 6 & $7,00 \pm 5,36$ \\
\hline $39 \mathrm{KDa}$ & 7 & $\begin{array}{l}10,42 \pm \\
2,69 \mathrm{C}\end{array}$ & 7 & $\begin{array}{c}10,57 \pm \\
3,50 \mathrm{C}\end{array}$ & 7 & $\begin{array}{c}11,00 \pm \\
3,87 \mathrm{C}\end{array}$ & 4 & $\begin{array}{c}10,57 \pm \\
4,19 \mathrm{C}\end{array}$ & 6 & $\begin{array}{c}12,00 \pm \\
4,4272 \mathrm{C}\end{array}$ & 7 & $\begin{array}{l}13,14 \pm \\
5,39 \mathrm{BC}\end{array}$ & 8 & $\begin{array}{l}17,37 \pm \\
5,63 \mathrm{AB}\end{array}$ & 6 & $\begin{array}{c}19,50 \pm \\
7,71 \mathrm{~A}\end{array}$ \\
\hline $41 \mathrm{KDa}$ & 8 & $\begin{array}{l}58,37 \pm \\
24,47 \mathrm{C}\end{array}$ & 7 & $\begin{array}{l}69,00 \pm \\
6,73 \mathrm{BC}\end{array}$ & 7 & $\begin{array}{c}73,28 \pm \\
19,61 \mathrm{BC}\end{array}$ & 4 & $\begin{array}{c}78,28 \pm \\
23,67 \mathrm{BC}\end{array}$ & 6 & $\begin{array}{c}72,50 \pm \\
28,17 \mathrm{BC}\end{array}$ & 7 & $\begin{array}{c}79,71 \pm \\
37,98 \mathrm{BC}\end{array}$ & 8 & $\begin{array}{c}96,12 \pm \\
31,85 \mathrm{AB}\end{array}$ & 6 & $\begin{array}{l}116,50 \pm \\
36,85 \mathrm{~A}\end{array}$ \\
\hline $175 \mathrm{KDa}$ & 8 & $\begin{array}{c}144,00 \pm \\
107,44\end{array}$ & 7 & $\begin{array}{c}158,29 \pm \\
51,71\end{array}$ & 7 & $\begin{array}{c}174,29 \pm \\
50,43\end{array}$ & 4 & $\begin{array}{c}187,00 \pm \\
50,84\end{array}$ & 6 & $\begin{array}{c}172,00 \pm \\
58,89\end{array}$ & 7 & $\begin{array}{c}172,14 \pm \\
20,60\end{array}$ & 8 & $\begin{array}{c}145,25 \pm \\
48,59\end{array}$ & 6 & $\begin{array}{c}176,33 \pm \\
50,87\end{array}$ \\
\hline $28 \mathrm{KDa}$ & 8 & $\begin{array}{c}791,75 \pm \\
206,54\end{array}$ & 7 & $\begin{array}{c}801,29 \pm \\
148,56\end{array}$ & 7 & $\begin{array}{c}840,86 \pm \\
97,65\end{array}$ & 4 & $\begin{array}{c}887,57 \pm \\
90,03\end{array}$ & 6 & $\begin{array}{c}890,67 \pm \\
133,92\end{array}$ & 7 & $\begin{array}{c}797,29 \pm \\
95,61\end{array}$ & 8 & $\begin{array}{c}866,38 \pm \\
102,41\end{array}$ & 6 & $\begin{array}{c}865,67 \pm \\
132,13\end{array}$ \\
\hline $50 \mathrm{KDa}$ & 8 & $\begin{array}{c}638,13 \pm \\
236,58\end{array}$ & 7 & $\begin{array}{c}693,43 \pm \\
104,05\end{array}$ & 7 & $\begin{array}{c}748,86 \pm \\
143,57\end{array}$ & 4 & $\begin{array}{c}841,29 \pm \\
142,71\end{array}$ & 6 & $\begin{array}{c}757,83 \pm \\
145,88\end{array}$ & 7 & $\begin{array}{c}825,29 \pm \\
191,69\end{array}$ & 8 & $\begin{array}{c}796,25 \pm \\
305,71\end{array}$ & 6 & $\begin{array}{c}715,67 \pm \\
133,40\end{array}$ \\
\hline $83 \mathrm{KDa}$ & 8 & $\begin{array}{c}1236,3 \pm \\
1724,0 \mathrm{AB}\end{array}$ & 7 & $\begin{array}{c}600,29 \pm \\
104,17 \mathrm{AB} \\
\end{array}$ & 7 & $\begin{array}{c}587,71 \pm \\
77,10 \mathrm{~B} \\
\end{array}$ & 4 & $\begin{array}{r}606,57 \pm \\
84,49 \mathrm{AB} \\
\end{array}$ & 6 & $\begin{array}{r}592,50 \pm \\
71,74 \mathrm{AB}\end{array}$ & 7 & $\begin{array}{c}579,71 \pm \\
55,71 \mathrm{~B} \\
\end{array}$ & 8 & $\begin{array}{l}689,63 \pm \\
143,62 \mathrm{~A} \\
\end{array}$ & 6 & $\begin{array}{r}598,83 \pm \\
83,73 \mathrm{AB} \\
\end{array}$ \\
\hline
\end{tabular}

As letras maiúsculas $(\mathrm{A}$ e $\mathrm{B})$ representam diferença estatística $(\mathrm{P}<0.05)$ entre os momentos/colunas. 
Tabela 2. Média e desvio-padrão das concentrações das frações proteicas $(\mathrm{mg} / \mathrm{dL})$ e da proteína total $(\mathrm{g} / \mathrm{dL})$ nos potros provenientes de éguas com placentite ascendente nos momentos: imediatamente após o nascimento (C1), 12 horas (C2), 24 horas (C3) e 48 horas após o nascimento (C4)

\begin{tabular}{ccccccccc}
\hline $\begin{array}{c}\text { Proteínas/Frações } \\
\text { proteicas }\end{array}$ & $\mathrm{N}$ & $\mathrm{C} 1$ & $\mathrm{~N}$ & $\mathrm{C} 2$ & $\mathrm{~N}$ & $\mathrm{C} 3$ & $\mathrm{~N}$ & $\mathrm{C} 4$ \\
\hline $\mathrm{PT}(\mathrm{g} / \mathrm{dL})$ & 7 & $4,3 \pm 0,4$ & 8 & $4,9 \pm 0,4$ & 7 & $5,4 \pm 0,4$ & 4 & $5,4 \pm 0,6$ \\
$63 \mathrm{KDa}$ & 7 & $3311 \pm 244$ & 8 & $3240 \pm 228$ & 7 & $3288 \pm 244$ & 4 & $3235 \pm 323$ \\
$102 \mathrm{KDa}$ & 7 & $11,6 \pm 3,5$ & 8 & $11,1 \pm 3,2$ & 7 & $11,3 \pm 3,5$ & 4 & $11,2 \pm 4,6$ \\
$39 \mathrm{KDa}$ & 7 & $8,9 \pm 3,6$ & 8 & $11,8 \pm 3,4$ & 7 & $19,2 \pm 3,6$ & 4 & $16,7 \pm 4,8$ \\
$41 \mathrm{KDa}$ & 7 & $64 \pm 19$ & 8 & $60 \pm 18$ & 7 & $76 \pm 19$ & 4 & $50,5 \pm 25$ \\
$175 \mathrm{KDa}$ & 7 & $91 \pm 21$ & 8 & $90 \pm 19$ & 7 & $86 \pm 21$ & 4 & $80 \pm 28$ \\
$28 \mathrm{KDa}$ & 7 & $3,3 \pm 113 \mathrm{~B}$ & 8 & $229 \pm 105 \mathrm{~A}$ & 7 & $373 \pm 113 \mathrm{~A}$ & 4 & $402 \pm 149 \mathrm{~A}$ \\
$50 \mathrm{KDa}$ & 7 & $6,2 \pm 133 \mathrm{~B}$ & 8 & $291 \pm 125 \mathrm{~A}$ & 7 & $474 \pm 133 \mathrm{~A}$ & 4 & $541 \pm 177 \mathrm{~A}$ \\
IgG Total & 7 & $34 \pm 240 \mathrm{~B}$ & 8 & $521 \pm 225 \mathrm{~A}$ & 7 & $847 \pm 240 \mathrm{~A}$ & 4 & $943 \pm 318 \mathrm{~A}$ \\
$83 \mathrm{KDa}$ & 7 & $533 \pm 55$ & 8 & $507 \pm 51$ & 7 & $504 \pm 55$ & 4 & $489 \pm 72$ \\
\hline
\end{tabular}

As letras maiúsculas $(\mathrm{A}$ e $\mathrm{B})$ representam diferença estatística $(\mathrm{P}<0.05)$ entre os momentos/colunas.

\section{AGRADECIMENTOS}

Ouro Fino Agronegócio, Fapergs, CNPQ, Capes.

\section{REFERÊNCIAS}

BAILEY, C.S.; MACPHERSON, M.L.; POZOR, M.A. et al. Treatment efficacy of trimethoprimsulfamethoxazole, pentoxifylline and altrenogest in experimentally induced equine placentitis. Theriogenology, v.74, p.402-412, 2010.

CANISSO, I.F.; BALL, B.A.; CRAY, C. et al. Serum amyloid a and hatoglobin concentrations are increased in plasma of mares with ascending placentitis in the absence of changes in peripheral leukocyte counts or fibrinogen concentration. J. Am. Reprod. Immunol., v.72, p.376-385, 2014.

CANISSO, I.F.; BALL, B.A.; SCOGGIN , K.E. et al., Alpha-fetoprotein is present in the fetal fluids and is increased in plasma of mares with experimentally induced ascending placentitis. Anim. Reprod. Sci., 2015.

Available

in: <http://dx.doi.org/10.1016/j.anireprosci.2014.12.019>. Accessed in: 19 fev. 2016.

COHEN, N. Causes of and farm management factors associated with disease and death in foals. J. Am. Vet. Med. Assoc., v.204, p.1644-1651, 1994.

CRISMAN, M.V.; SCARRATT, W.K.; ZIMMERMAN, K.L. Blood proteins and inflammation in the horse. Vet. Clin. Equine, v.24, p.285-297, 2008.

ECKERSALL, P.D.; BELL, R. Acute phase proteins: biomarkers of infection and inflammationin veterinary medicine - review. Vet. J., v.185, p.23-27, 2010.
FAGLIARI, J.J.; WEISS, D.J.; McCLENAHAN, D. et al. Serum protein concentrations in calves with experimentally induced pneumonic pasteurellosis. Arq. Bras. Med. Vet. Zootec., v.55, p.383-387, 2003.

GILES, R.C.; DONAHUE, J.M.; HONG C.B. et al. Causes of abortion, stillbirth, and perinatal death in horses: 3,527 cases (1986-1991). J. Am. Vet. Med. Assoc., v.203, p.1170-1175, 1993.

HONG, C.B.; DONAHUE, J.M.; GILES Jr., R.C. et $a l$. Etiology and pathology of equine placentitis, $J$. Vet. Diag. Invest., v.5, p.56-63, 1993.

KANEKO, J.J.; HARVEY, J.W.; BRUSS, M.L. Clinical biochemistry of domestic animals. 5.ed. San Diego: Academic Press, 1997. 932p.

LAEMMLI, U.K. Cleavage of structural proteins during the assembly of the head of bacteriophage T4. Nature, v.227, p.680-685, 1970.

LEBLANC, M.M. Ascending placentitis in the mare: an update. Reprod. Domest. Anim., v.45, p.28-34, 2010.

LINS, L.A.; FINGER, I.S.; FERNANDES, C.G. et al. Resposta clínica e metabólica de potros neonatos em relação aos achados histopatológicos da placenta na égua. Arq. Bras. Med. Vet. Zootec., v.64, p.1436-1441, 2012.

MURATA, H.; SHIMADA, N.; YOSHIOKA, M. Current research on acute phase proteins in veterinary diagnosis: an overview. Vet. J., v.168, p.28-40, 2004.

SCHLAFER, D. Postmortem examination of the equine placenta, fetus, and neonate: methods and interpretation of findings. Proc. Am. Assoc. Equine Pract., v.50, p.144-161, 2004.

TAKIGUCHI, M.; FUJINAGA, T.; NAIKI, M. et al. Isolation, characterization, and quantitative analysis of C-reative protein from horses. Am. J. Vet. Res., v.51, p.1215-1220, 1990. 